\title{
Stretching DNA in polymer nanochannels fabricated by thermal imprint in PMMA
}

\author{
Thamdrup, Lasse Højlund; Klukowska, A.; Kristensen, Anders
}

Published in:

Nanotechnology

Link to article, DOI:

10.1088/0957-4484/19/12/125301

Publication date:

2008

Link back to DTU Orbit

Citation (APA):

Thamdrup, L. H., Klukowska, A., \& Kristensen, A. (2008). Stretching DNA in polymer nanochannels fabricated by thermal imprint in PMMA. Nanotechnology, 19(12). https://doi.org/10.1088/0957-4484/19/12/125301

\section{General rights}

Copyright and moral rights for the publications made accessible in the public portal are retained by the authors and/or other copyright owners and it is a condition of accessing publications that users recognise and abide by the legal requirements associated with these rights.

- Users may download and print one copy of any publication from the public portal for the purpose of private study or research.

- You may not further distribute the material or use it for any profit-making activity or commercial gain

- You may freely distribute the URL identifying the publication in the public portal

If you believe that this document breaches copyright please contact us providing details, and we will remove access to the work immediately and investigate your claim. 


\title{
Stretching DNA in polymer nanochannels fabricated by thermal imprint in PMMA
}

\author{
Lasse H. Thamdrup ${ }^{1}$, Anna Klukowska ${ }^{2}$ and Anders \\ Kristensen ${ }^{1}$ \\ ${ }^{1}$ NanoDTU, MIC - Department of Micro and Nanotechnology, Technical University \\ of Denmark, DK-2800 Lyngby, Denmark \\ 2 micro resist technology GmbH, D-12555 Berlin, Germany \\ E-mail: ak@mic.dtu.dk
}

\begin{abstract}
We present results regarding the fast and inexpensive fabrication of polymer biochips for investigating the statics and dynamics of DNA confined in nanochannels. The biochips have been fabricated by means of nanoimprint lithography (NIL) in low molecular weight polymethyl methacrylate (PMMA) using a 4 inch diameter two-level hybrid stamp. The fluidic structures were sealed using thermal polymer fusion bonding. The stamp has nanometer- and micrometer-sized protrusions defined in a thermally grown $\mathrm{SiO}_{2}$ layer and the sol-gel process derived duromeric polymer Ormocomp respectively. The stamp is compatible with molecular vapor deposition (MVD), used for applying a durable chlorosilane based antistiction coating, and allows for imprint up to a temperature of $270^{\circ} \mathrm{C}$. The extension of YOYO-1 stained T4 GT7 bacteriophage DNA inside the PMMA nanochannels has been experimentally investigated using epi-fluorescence microscopy. The measured average extension length amounts to $20 \%$ of the full contour length with a standard deviation of $4 \%$. These results are in good agreement with results obtained by stretching DNA in conventional fused silica nanochannels.
\end{abstract}

Submitted to: Nanotechnology 


\section{Introduction}

Currently, lab-on-a-chip (LOC) applications with passive nanofluidic structures are being utilized for investigating DNA confined inside structures that have dimensions comparable to the biomolecule persistence length (i.e. $P=50 \mathrm{~nm}$ [1]). The work entails real-time contour length measurements of DNA stretched inside nanochannels $[2$, 3, 4], filtering of multi-disperse DNA samples [5], investigation of DNA diffusion in nanoslits [6], entropic recoil effects observed at the interface between micro- and nanofluidic structures [7] and restriction mapping inside nanochannels using restriction endonucleases [8]. The major advantage of incorporating nanofluidic structures is the possibility of probing and investigating single DNA molecules on the appropriate length scale. This allows for extracting information which is not accessible when the DNA assumes its bulk solution coiled-up conformation.

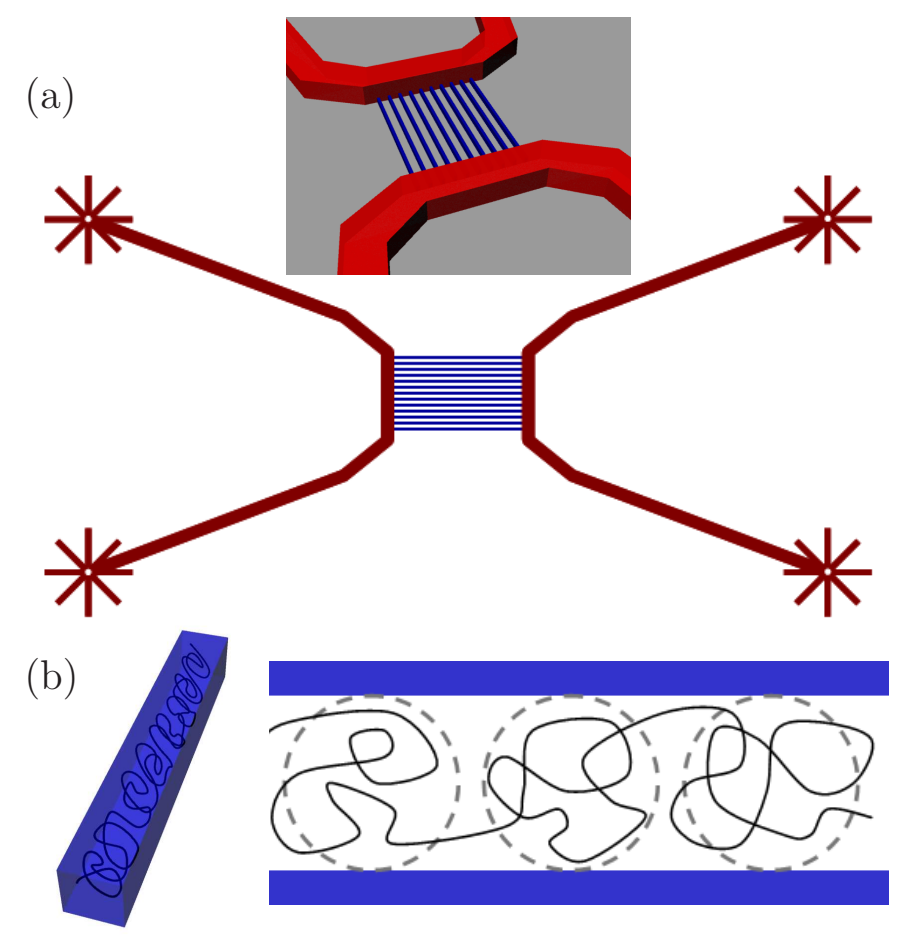

Figure 1. (a) Schematic of a part of the fabricated two-level hybrid stamp showing the V-shaped micrometer-sized protrusions (width of $50 \mu \mathrm{m}$ and height of $1 \mu \mathrm{m}$ ) defined in Ormocomp and the nanometer-sized protrusions (width and height of $250 \mathrm{~nm}$ and a pitch of $750 \mathrm{~nm}$ ) defined in a dry thermal $\mathrm{SiO}_{2}$ layer. The distance between the two $\mathrm{V}$-shaped protrusions is $500 \mu \mathrm{m}$. The 4 inch stamp allows for imprinting four identical biochips with a size of $2.54 \mathrm{~cm} \times 2.54 \mathrm{~cm}$. The inset shows an artistic 3D impression of the stamp. (b) Schematics showing the conformation of linear DNA when confined inside the PMMA nanochannels. The DNA molecule stretches out in a series of blobs. The extension length $L_{\text {ext }}$ is proportional to the total contour length $L$ of the molecule in the de Gennes regime where the DNA persistence length $P$ is smaller than the cross-sectional dimensions of the confining channel. 
Conventionally, planar processing of fused silica substrates has been employed for making these LOC applications since this offers an easy route towards fabricating devices that implements fluidic structures with varying lateral and vertical dimensions. However, this approach is both slow and expensive which represents an inherent drawback of the fused silica based fabrication scheme. Nanoimprint lithography (NIL) [9], also known as thermal imprint, is basically a process in which the inverse topology of a master stamp is transferred to a polymer, which may be duromeric or thermoplastic, by means of plastic deformation. During the past decade, extensive research has been conducted within this field [10, 11], thereby introducing NIL as a highly versatile and competitive platform for micro- and nanofabrication. Furthermore new elaborate variants such as roll-to-roll imprint [12] and combined-nanoimprint-andphotolithography [13] have emerged. The imprinted polymer layer may serve as an etch mask, a template for lift-off processes or as a functional part of polymer LOC applications, the latter being the subject of this article. Utilizing NIL to fabricate cheap and disposable polymer devices in a single imprint is highly appealing. Stamps, for producing polymer devices with fluidic structures having lateral dimensions ranging from the nanometer to the micrometer scale, are easily fabricated using a mix-and-match process [14]. From the fabricational point of view it is less trivial to produce a stamp where not only the width but also the height of the protrusions varies. We present a fabrication scheme for making a 4 inch two-level hybrid stamp. Using the stamp, polymethyl methacrylate (PMMA) biochips, containing microfluidic channels for bulk sample transport and nanofluidic channels for stretching DNA, have been produced in a single imprint step followed by thermal polymer fusion bonding. As thermal imprint in PMMA requires a temperature in excess of the glass transition temperature of $105^{\circ} \mathrm{C}$ and high imprint forces [9], the utilized stamp must be hard and rigid which effectively prohibits the use of elastomeric materials such as polydimethylsiloxane (PDMS) - an elastomer that has found widespread use as a mold material capable of replicating nanoscale features in soft lithography processes [15]. A schematic showing part of the stamp may be seen in figure 1 (a). Two V-shaped protrusions, having a width of $50 \mu \mathrm{m}$ and a height of $1 \mu \mathrm{m}$, are bridged by an array of nanometer-sized protrusions having a width and height of $250 \mathrm{~nm}$. As illustrated in figure 1 (b), DNA molecules, confined inside the polymer nanochannels, will stretch out in a series of blobs and the extension length is proportionally related to the overall contour length of the confined molecule [2].

\section{Fabrication}

The overall process flow for fabricating the polymer biochips is composed of four major steps as seen in the schematic presented in figure 2. Initially, a $250 \mathrm{~nm}$ thick dry thermal $\mathrm{SiO}_{2}$ layer was grown on a 4 inch silicon substrate with a thickness of $500 \mu \mathrm{m}$. The thickness of the oxide layer determines the final height of the nanoscale protrusions. The oxidized wafer was dehydrated on a hotplate at $200^{\circ} \mathrm{C}$ for 10 min before spin coating the chemically amplified resist (CAR) formulation SU-8 (MicroChem Corp., SU-8 2002 
diluted with pure cyclopentanone to give a $14.5 \mathrm{wt} \%$ solution). SU-8 is a highly sensitive negative resist with a resolution of approximately $24 \mathrm{~nm}$ however, the relatively low contrast prohibits the use of SU-8 if the pitch is below $300 \mathrm{~nm}$ [16]. A pre-exposure bake at $90^{\circ} \mathrm{C}$ for 1 min was performed to drive out the solvent and subsequently $100 \mathrm{kV}$ electron beam lithography (EBL using JEOL-JBX9300FS) was carried out in order to define the array of $250 \mathrm{~nm}$ wide and $500 \mu \mathrm{m}$ long lines in the $280 \mathrm{~nm}$ thick SU-8 layer. An optimal dose of $10 \mu \mathrm{C} / \mathrm{cm}^{2}$ was used. The exposed wafer was given a post-exposure bake at $90^{\circ} \mathrm{C}$ for $1 \mathrm{~min}$ before development in propylene glycol monomethyl ether acetate (i.e. PGMEA). After development the wafer was flushed with isopropanol. Before the oxide etch, the wafer was subjected to a descumming process [17] in order to remove residual SU-8 in unexposed areas. The unmasked $\mathrm{SiO}_{2}$ was removed in a $\mathrm{CF}_{4} / \mathrm{CHF}_{3}$ based reactive ion etch (RIE) process [14] (STS C010 Multiplex Cluster System) which has an oxide etch rate of $33 \mathrm{~nm} / \mathrm{min}$, a selectivity between $\mathrm{SiO}_{2}$ and SU-8 of 1.6 and a selectivity between $\mathrm{SiO}_{2}$ and silicon of 6 . Defining the array of nanoscale protrusions in a dry thermal $\mathrm{SiO}_{2}$ layer has two distinct advantages: $(i)$ The thickness of dry thermal oxides may be controlled on the nanometer scale by changing the growth temperature and time and furthermore the 4 inch wafer scale thickness variation is negligible [18] and $(i i)$ due to the relatively high $\mathrm{SiO}_{2}$-Si selectivity, the silicon substrate functions as an effective etch stop thus minimizing loading effects from the RIE process.

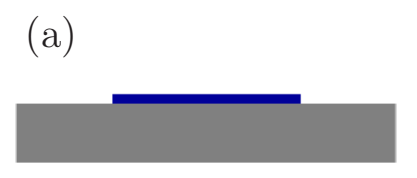

(b)

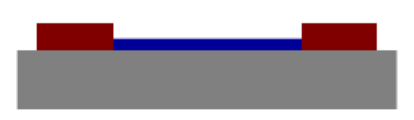

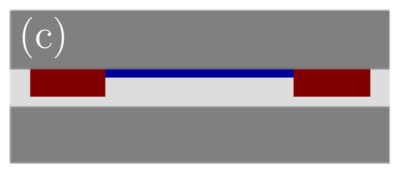

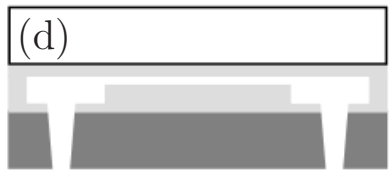

Figure 2. Schematic of the process flow for producing the polymer biochips: (a) Dry thermal oxidation and subsequently EBL in SU-8 and RIE to define the array of nanoscale protrusions, (b) spin coating Ormocomp and performing UVL and thermal curing to define V-shaped micrometer-sized protrusions, (c) deposition of chlorosilane based antistiction coating on the stamp using MVD and NIL in $50 \mathrm{k}$ PMMA and (d) sandblasting liquid access holes in the imprinted wafer followed by thermal polymer fusion bonding of a Pyrex substrate with a thin $50 \mathrm{k}$ PMMA layer.

The V-shaped micrometer-sized protrusions were defined in Ormocomp (micro resist technology $\mathrm{GmbH}$, diluted with ma-T 1050 to give a 29 wt\% solution) which is a silicon containing sol-gel process derived duromeric ORMOCER ${ }^{\circledR}$ material [19]. Ormocomp has three advantages as a material for fabricating NIL stamps: $(i)$ It behaves like a negative CAR formulation and may therefore be patterned using ultraviolet lithography (UVL) and thermal curing, ( $i$ i) a durable antistiction coating may be applied using molecular vapor deposition (MVD) and ( $i i i)$ the cured structures should ideally show no degradation at temperatures below $270^{\circ} \mathrm{C}$. Before spin coating Ormocomp, the 
wafer was dehydrated at $200^{\circ} \mathrm{C}$ for $10 \mathrm{~min}$. An approximately $1.1 \mu \mathrm{m}$ thick Ormocomp layer was subsequently spin coated and the wafer was pre-exposure baked at $100^{\circ} \mathrm{C}$ for 5 min. As the uncured Ormocomp is a viscous liquid, UVL (EVC Aligner AL6-2) was performed in proximity mode with a gap between mask and substrate of $5 \mu \mathrm{m}$. A dose of $160 \mathrm{~mJ} / \mathrm{cm}^{2}$ was utilized. Afterwards the wafer was post-exposure baked at $90^{\circ} \mathrm{C}$ for $3 \mathrm{~min}$ before developing in Ormodev (micro resist technology $\mathrm{GmbH}$ ) and flushing with isopropanol. To increase the hardness and substrate adhesion of the Ormocomp structures, a flood exposure, using a dose of $1000 \mathrm{~mJ} / \mathrm{cm}^{2}$, was carried out and the wafer was left on a hotplate at $150^{\circ} \mathrm{C}$ for $3 \mathrm{~h}$. The final Ormocomp protrusion height was $1 \mu \mathrm{m}$. Before thermal imprint, a durable antistiction coating was applied using MVD (MVD100, Applied Microstructures Inc.). In this process, a conformal monolayer is deposited when the chlorosilane based precursor $(1 \mathrm{H}, 1 \mathrm{H}, 2 \mathrm{H}, 2 \mathrm{H}$-perfluorodecyltriclorsilane) reacts covalently with hydroxyl groups, formed during an initial oxygen plasma treatment, on the substrate [20]. The self-assembled monolayer increases the surface energy of the stamp thereby preventing adhesion of polymer material during imprint. Scanning electron microscopy (SEM) images of the fabricated stamp may be seen in figure 3 (a).
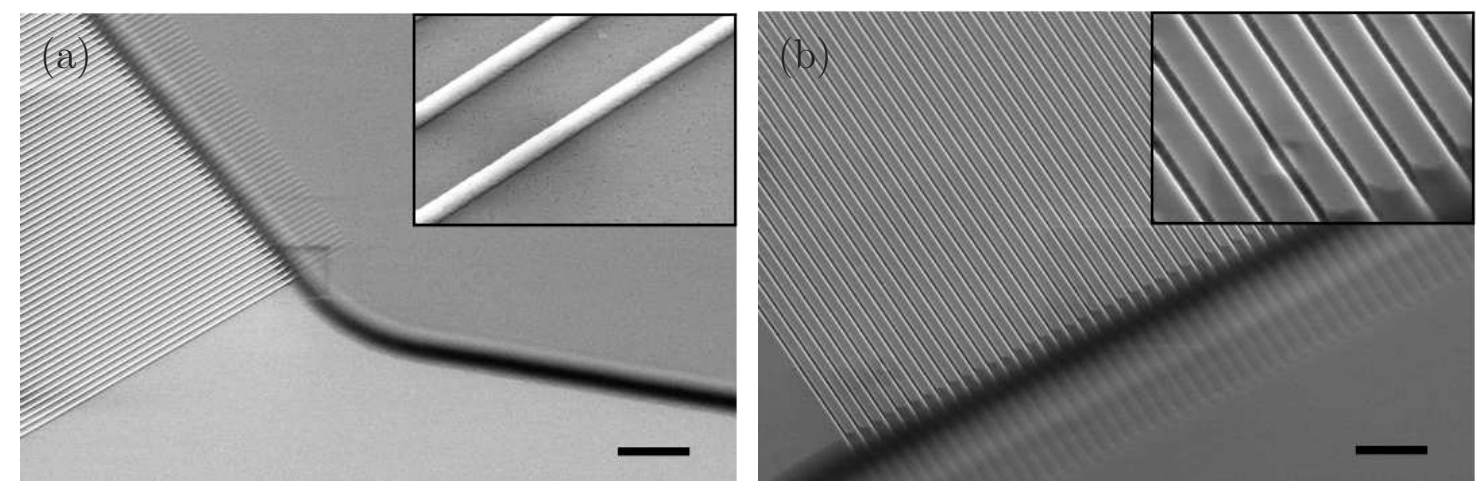

Figure 3. (a) SEM image of the fabricated stamp. $10 \mathrm{~nm} \mathrm{Au}$ has been deposited prior to inspection and the scale bar is $5 \mu \mathrm{m}$. The image shows the interface between a micrometer-sized protrusion defined in Ormocomp and the array of nanometersized protrusions defined in a dry thermal $\mathrm{SiO}_{2}$ layer. The inset shows a zoom-in on the slightly isotropic nanometer-sized $\mathrm{SiO}_{2}$ protrusions having a width and height of $250 \mathrm{~nm}$. (b) SEM image showing an imprint in $50 \mathrm{k}$ PMMA. The image shows the interface between micro- and nanofluidic channels. $10 \mathrm{~nm} \mathrm{Al}$ has been deposited prior to inspection and the scale bar is $10 \mu \mathrm{m}$. The inset shows a zoom-in on the imprinted nanochannels.

Thermal imprint was performed in PMMA (MicroChem Corp., $50 \mathrm{k}$ PMMA dissolved in pure anisole to give a $30 \mathrm{wt} \%$ solution) which is a well known thermoplastic polymer introduced for NIL by Chou et al. in their pioneering work [9]. PMMA has a water absorption of $0.3 \%$ [21], a glass transition temperature of $T_{\mathrm{g}}=105^{\circ} \mathrm{C}$ [9] and a high optical transmission and low autofluorescence at wavelengths in the interval 400$1000 \mathrm{~nm}$ [22]. The relatively low water absorption and autofluorescence of PMMA makes it a suitable material for producing biochips. Prior to imprint, a $2.8 \mu \mathrm{m}$ thick PMMA 
layer was spin coated on a silicon substrate which had been dehydrated at $200^{\circ} \mathrm{C}$ for $10 \mathrm{~min}$. In order to drive out the solvent, the thin film coated wafer was left on a hotplate at $150^{\circ} \mathrm{C}$ for 30 min. Thermal imprint (EV Group 520 Hot Embosser) was performed at a temperature of $190^{\circ} \mathrm{C}$ using a piston force of $10 \mathrm{kN}$ and an imprint time of $15 \mathrm{~min}$. The chamber pressure during imprint was approximately $10^{-2} \mathrm{mbar}$ and the stamp was released from the imprint manually at $60^{\circ} \mathrm{C}$. After the NIL process, liquid access holes, with a diameter of $1 \mathrm{~mm}$, were sandblasted through the silicon substrate using a dedicated micro-etching tool (Microetcher II, Danville Engineering). In order to protect the imprint, $70 \mu \mathrm{m}$ thick Nitto SWT blue film with $\mathrm{CO}_{2}$ laser marked holes was used as a masking material [18]. SEM images of the imprint are presented in figure 3 (b). The imprinted micrometer- and nanometer-sized features have a high pattern replication fidelity.

A vast number of techniques for sealing polymer fluidic applications have been developed. These include solvent or oxygen plasma assisted bonding, lamination and thermal polymer fusion bonding [23, 24, 25, 26, 27]. Furthermore Guo et al. introduced a simple technique in which channel structures are sealed by the stamp itself in a NIL process relying on incomplete cavity filling [28]. The technique was used for fabricating sealed nanochannels with a minimum width and height of $75 \mathrm{~nm}$ and $120 \mathrm{~nm}$ respectively. However, the method clearly does not allow for reusing the rigid glass or silicon template and this represents an inherent drawback. Furthermore the technique is incompatible with the fabrication of homogenous all-polymer nanochannels. We have utilized a simple thermal polymer fusion bonding scheme in order to seal the imprinted fluidic structures. PMMA (Microchem Corp., $50 \mathrm{k}$ PMMA dissolved in pure anisole to give a $10 \mathrm{wt} \%$ solution) was spin coated on a 4 inch Pyrex substrate which had been dehydrated at $200^{\circ} \mathrm{C}$ for $10 \mathrm{~min}$. The thin film coated Pyrex substrate was subsequently left on a hotplate at $150^{\circ} \mathrm{C}$ for $1.5 \mathrm{~min}$ to drive out the solvent. To prevent degradation of the imprinted structures, bonding should be performed using a low temperature and piston force. Thermal polymer fusion bonding is believed to be mediated by polymer chain entanglements at the bonding interface [29]. This suggests that temperature is the vital parameter in obtaining a durable high strength bond, whereas the applied piston force should just be sufficient as to ensure conformal contact between the thin film coated substrates. Experimental investigations of thermal polymer fusion bonding suggests, that an optimal bond strength of $\sim 15 \mathrm{MPa}$ can be achieved at a temperature $\sim 15 \%$ above $T_{\mathrm{g}}[27,29]$. For our specific application, the preservation of the imprinted fluidic structures is more important than an exceedingly high bond strength. Therefore bonding (EV Group 520 Hot Embosser) was carried out at $T_{\mathrm{g}}=105^{\circ} \mathrm{C}$ using a piston force of $3 \mathrm{kN}$ and a bonding time of $10 \mathrm{~min}$. The bond strength has not been investigated (e.g. by pull-tests) however, the bond is durable enough to withstand dicing and no indications of liquid leakage has been observed during DNA extension measurements. 


\section{DNA preparation and buffer chemistry}

In this article, the entropically induced stretching of T4 GT7 bacteriophage DNA (Nippon Gene Co., Ltd.) inside PMMA nanochannels was investigated. T4 DNA has 166 kilobase pairs and assuming a spacing between base pairs of $0.34 \mathrm{~nm}$ [30] the fully stretched contour length is $L=56.4 \mu \mathrm{m}$. The DNA was stained using the bisintercalating dimeric cyanine dye YOYO-1 (Molecular Probes) at a ratio of 1 dye molecule per 5 base pairs. The bisintercalating binding mode has been illustrated in figure 4. Upon DNA binding, the fluorescence of YOYO-1 is enhanced by a factor of 3000 [31] making it ideal for high sensitivity epi-fluorescence measurements. The influence of YOYO-1 bisintercalation on the contour and persistence length of DNA has been experimentally investigated $[32,33,34]$. These studies suggest that $L$ and $P$ are increased by $30 \%$ at a saturating staining ratio of 1 dye molecule per 4 base pairs. The increase in $L$ is intuitively understood since YOYO-1, upon binding, causes a local deformation of the double helix. The increase in $P$ is more subtle. The intercalation event causes $(i)$ a local mechanical increase in the double helix rigidity which increases $P$ and $(i i)$ a reduction of the electrostatic interactions between segments of the negatively charged DNA backbone, due to the positive charge of YOYO-1 [35], which serve as to reduce $P$. At our staining ratio, which is $80 \%$ of full dying, we will assume a $24 \%$ increase in $L$ and $P$ thus resulting in $L_{\text {dye }} \approx 70 \mu \mathrm{m}$ and $P_{\text {dye }} \approx 62 \mathrm{~nm}$.

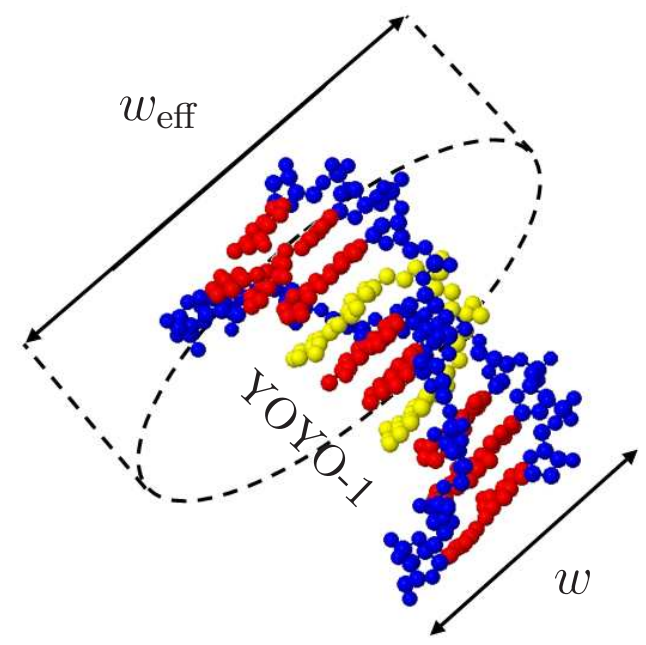

Figure 4. Schematic illustration of the bisintercalation of the fluorescent dye YOYO1. Furthermore the inherent double helix width $w$ and the effective width $w_{\text {eff }}$ are shown on the figure.

The loading buffer, used for pre-wetting the polymer chips, consisted of $0.0045 \mathrm{M}$ tris-base, $1 \mathrm{mM}$ ethylenediaminetetraacetic acid (i.e. EDTA) with $0.0045 \mathrm{M}$ boric acid (commonly abbreviated $0.05 \times \mathrm{TBE}$ ) and $50 \mathrm{mM} \mathrm{NaCl}$. The experimental buffer, prepared prior to measurements, consisted of YOYO-1 stained T4 DNA dissolved in the loading buffer and $3 \% \beta$-mercaptoethanol, $4 \mathrm{mg} / \mathrm{ml} \beta$-D-glucose, $0.2 \mathrm{mg} / \mathrm{ml}$ glucose- 
oxidase and $0.04 \mathrm{mg} / \mathrm{ml}$ catalase was added to suppress photo-bleaching of YOYO-1 and photo-nicking of DNA [4]. The intrinsic width $w$ of the DNA double helix is approximately $2 \mathrm{~nm}$ [30]. However, the effective width $w_{\text {eff }}$, taking electrical screening of the negative DNA backbone by ions in the buffer solution into account, is highly dependant on the monovalent salt content and in a $50 \mathrm{mM} \mathrm{NaCl}$ solution, an effective width of $7.4 \mathrm{~nm}$ is predicted [36].

\section{DNA extension measurements}

In the language of polymer physics, DNA is a semiflexible self-avoiding heteropolymer which is best described by the Kratky-Porod model [37]. The stiffness of the double helix makes DNA less flexible than ordinary ideal-chain-like polymers and the negatively charged phosphate groups on the backbone causes electrostatic repulsions between neighboring segments. In bulk solution, genomic length stained DNA assumes a coiledup conformation with a characteristic radius of gyration $R_{\mathrm{g}}=\left(P_{\mathrm{dye}} w_{\mathrm{eff}} L_{\text {dye }}^{3}\right)^{1 / 5}[38]$. Therefore the YOYO-1 stained T4 DNA, suspended in the experimental buffer, may be assumed to have $R_{\mathrm{g}} \approx 2.75 \mu \mathrm{m}$. Confining DNA inside fluidic structures where the geometric average of the cross-sectional dimensions $D=\sqrt{h w}, h$ and $w$ is the height and width, is much smaller than $R_{\mathrm{g}}$, prohibits the retainment of the coiled-up conformation. In the case where $R_{\mathrm{g}} \gg D \gg P$, often referred to as the de Gennes regime, the DNA molecule stretches out in a series of blobs along the confining nanochannel as seen in figure 1 (b). Based on scaling arguments, de Gennes showed that the extension length $L_{\text {ext }}$ is given by [39]

$$
L_{\text {ext }} \cong L_{\text {dye }}\left(\frac{w_{\text {eff }} P_{\text {dye }}}{D^{2}}\right)^{\frac{1}{3}} \text {. }
$$

As seen from (1), $L_{\text {ext }}$ is proportional to $L_{\text {dye }}$ and therefore stretching of DNA inside nanochannels provides $(i)$ a powerful method for determining the DNA size, $(i i)$ the possibility of probing interaction sites of proteins and enzymes and (iii) valuable information on the mechanical properties by observation of, for example, the thermal fluctuations of confined DNA. Based on (1), the expected extension length of confined T4 DNA is $L_{\mathrm{ext}} \approx 13.6 \mu \mathrm{m}$

Experimental epi-fluorescence measurements on confined T4 DNA were conducted on a modified Nikon microscope (Eclipse TE2000-U) coupled to an EMCCD camera (CascadeII, Photometrics). A $60 \times$ N.A.1.0 water immersion objective (Nikon) and a $1.5 \times$ lens (Nikon) fitted prior to the camera were used. Furthermore a metal halide illumination source (Prior Lumen 200W), coupled to the microscope via a liquid light guide, and a FITC filter (Ex: 465-495, DM: 505, BA: 515-555, Nikon) were used for excitation and filtering respectively. The polymer biochip was immersed in loading buffer and degassed for several days in order to ensure total wetting of the fluidic structures. Prior to measurements, the experimental buffer was injected into the liquid access holes. Bulk sample transport in the V-shaped microfluidic structures and translation of 
stretched DNA molecules along nanochannels was accomplished by pumping. A Single DNA molecule was pulled into a nanochannel and the extension was recorded at three specific locations 100, 250 and $400 \mu \mathrm{m}$ from the channel entrance. This was done for 10 different molecules. The confined DNA was imaged at a rate of 10 frames per second and a total of 500 frames were acquired during each measurement. The extension length $L_{\text {ext }}$ of a given DNA molecule in a single frame was extracted using a data analysis scheme presented in [2]. The average extension length $L_{\mathrm{av}}$ was subsequently taken as the mean of the 500 different values of $L_{\text {ext }}$. Experimental results are presented in figure 5 .
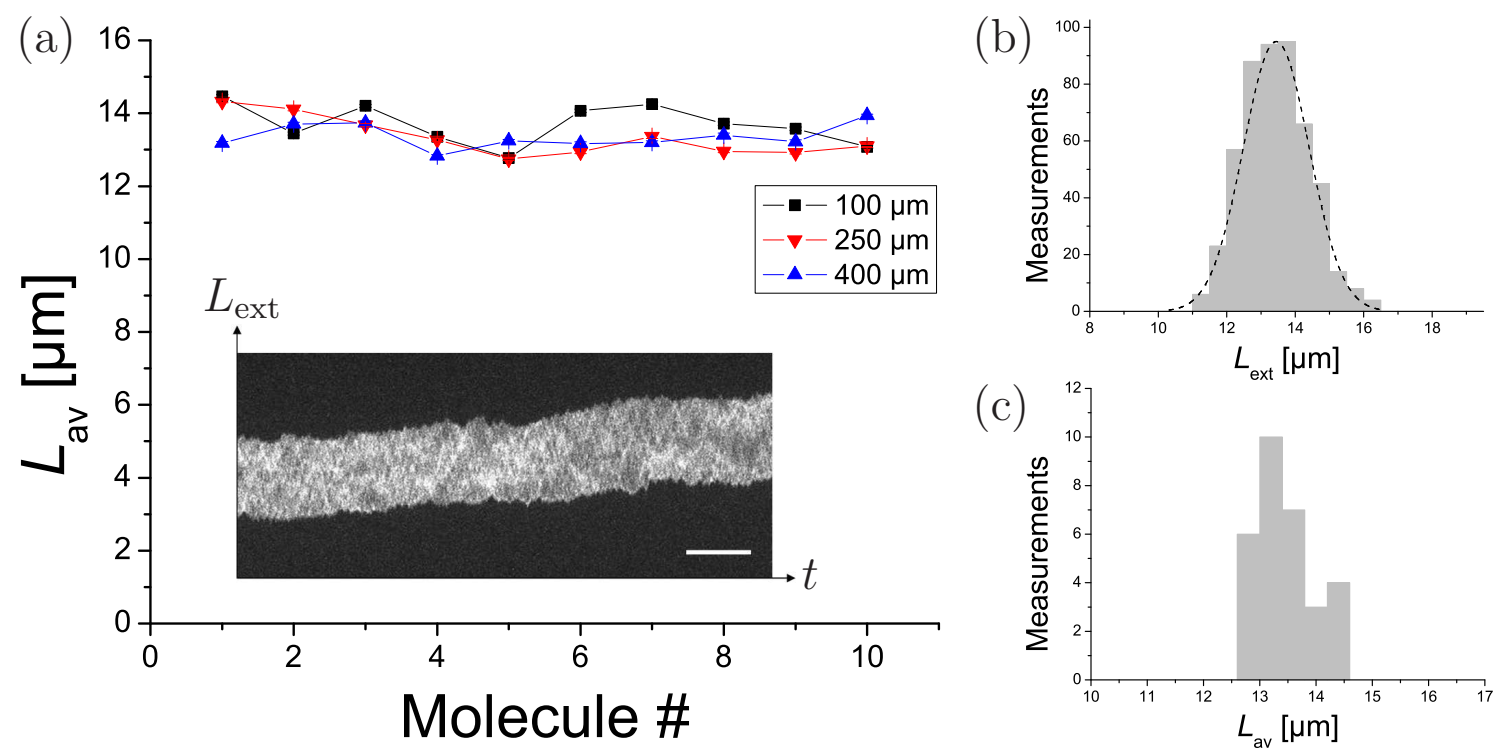

Figure 5. (a) Graphs showing the average extension length $L_{\mathrm{av}}$ of 10 different T4 DNA molecules. $L_{\text {av }}$ have been measured 100, 250 and $400 \mu \mathrm{m}$ from the nanochannel entrance for each molecule. The inset shows a typical intensity time-trace of a T4 molecule confined inside a PMMA nanochannel. The scale bar is $10 \mu \mathrm{m}$ and the time span is $50 \mathrm{~s}$. (b) Histogram of the measured extension lengths $L_{\text {ext }}$ of DNA molecule 2 positioned $100 \mu \mathrm{m}$ from the nanochannel entrance. The average extension length, based on analysis of 500 consecutive frames, $L_{\mathrm{av}}=13.4 \mu \mathrm{m}$ and the standard deviation $\sigma_{\mathrm{av}}=1.0 \mu \mathrm{m}$. The dashed line shows the Gaussian curve fit. (c) Histogram of the measured average extensions lengths $L_{\mathrm{av}}$ presented in (a). The overall average extension length is $13.5 \mu \mathrm{m}$ with a standard deviation of $0.5 \mu \mathrm{m}$.

Graphs showing $L_{\text {av }}$ measured 100, 250 and $400 \mu \mathrm{m}$ from the nanochannel entrance for 10 different molecules and a representative fluorescence timetrace are shown in figure 5 (a). As seen from the timetrace and the histogram in figure 5 (b), thermal fluctuations of the confined DNA leads to a Gaussian distribution in the measured values of $L_{\text {ext }}$ when considering single molecules. The mean value of the distribution is well described by (1) and in addition (2) [2] may be used for estimating the standard deviation $\sigma_{\mathrm{av}}$ due to small thermal fluctuations around $L_{\mathrm{av}}$.

$$
\sigma_{\mathrm{av}} \cong \sqrt{\frac{4 L_{\mathrm{dye}}}{15}\left(P_{\mathrm{dye}} w_{\mathrm{eff}} D\right)^{\frac{1}{3}}}
$$


(2) predicts $\sigma_{\mathrm{av}} \approx 1 \mu \mathrm{m}$ which is in excellent accordance with our experiments. Since the uncertainty in the average extension length $u_{\mathrm{av}}=\sigma_{\mathrm{av}} / \sqrt{N}$, where $N$ is the number of frames analyzed, the influence of thermal fluctuations may be suppressed by analyzing multiple frames. Ideally, this approach devises a route towards determining the contour length, and hence the number of nucleotides, with an arbitrary precision. In our experiments, where 500 consecutive frames were analyzed, $u_{\mathrm{av}} \approx 45 \mathrm{~nm}$ corresponding to 132 base pairs. However, as seen from figure 5 (a) and (c) there is another spread, not related to thermal fluctuations, in the measured values of $L_{\mathrm{av}}$. The overall measured average extension length and standard deviation is $13.5 \mu \mathrm{m}\left(20 \%\right.$ of $\left.L_{\text {dye }}\right)$ and $0.5 \mu \mathrm{m}$ ( $4 \%$ of $L_{\text {dye }}$ ) respectively. This spread is most likely to be caused by $(i)$ variations in the cross-sectional dimensions of the confining polymer nanochannels, $(i i)$ variations in the degree of interaction between confined DNA and the bounding surfaces or (iii) the existence of several stretched DNA conformations. Due to potential stamp bending in the thermal imprint process and nanochannel sagging during thermal polymer fusion bonding, it may initially be suspected that the cross-sectional dimensions of the polymer nanochannels are not constant. This would give rise to systematic entropically induced variations in the average extension length according to (1). However, measurements on DNA stretching in fusion bonded fused silica nanochannels [2, 3], that have a high degree of uniformity in terms of cross-sectional dimensions, exhibit an identical variance in the measured values of $L_{\mathrm{av}}$ when considering multiple stretched DNA molecules. The observed spread in the experimentally measured values of $L_{\mathrm{av}}$ in our measurements, is therefore not assigned to variations in the cross-sectional nanochannel dimensions. The observed spread in our measurements, and those presented in $[2,3]$, could be interpreted in terms of the existence of multiple semistable stretched DNA conformations. This in turn implies, that even though the random uncertainty, due to thermal fluctuations, may be minimized by analyzing multiple frames, the overall maximum resolution could be governed by transitions between different molecular conformations rather than thermal fluctuations.

\section{Conclusion}

We have developed a fabrication scheme for producing a two-level hybrid stamp composed of bulk silicon, dry thermal $\mathrm{SiO}_{2}$ and Ormocomp. The stamp may be antistiction coated using MVD and allows for performing thermal imprint up to a temperature of $270^{\circ} \mathrm{C}$. Polymer biochips have been fabricated by NIL in $50 \mathrm{k}$ PMMA and thermal polymer fusion bonding. The imprinted structures have a high pattern replication fidelity and no signs of stamp degradation have been observed after a total of 25 imprints. The entropically induced stretching of YOYO-1 stained T4 GT7 bacteriophage DNA inside PMMA nanochannels was investigated. An average extension length corresponding to $20 \%$ of the full contour length was observed. This value is in good agreement with an estimate based on de Gennes' model for a confined semiflexible self-avoiding polymer. The overall standard deviation in the measured average extension 
lengths of multiple confined DNA molecules is $4 \%$ of the full contour length which is in excellent accordance with similar measurements on DNA confined in fused silica nanochannels. From the presented results it is evident, that inexpensive and disposable polymer biochips represent a competitive alternative to conventional fused silica based applications when it comes to investigating DNA molecules confined inside nanofluidic structures. The polymer biochips may be fabricated using a simple imprint-and-bond scheme which is highly suitable for large scale production. Utilizing polymers for fabricating nanofluidic applications furthermore offers the additional benefit of allowing for an exploitation of the rich diversity in the chemistry and physical properties of commonly known thermoplastic polymers.

\section{Acknowledgments}

This work was financially supported by the Danish Research Council for Technology and Production, FTP grant number 274-050375. The partial support of the EC funded project NaPa (Contract no. NMP4-CT-2003-500120) is gratefully acknowledged. Furthermore the authors acknowledge Fredrik Persson for his experimental assistance.

\section{References}

[1] Bouchiat C, Wang M D, Allemand J F, Strick T, Block S M and Croquette V 1999 Biophys. J. 76409

[2] Tegenfeldt J, Prinz C and Cao H 2004 Proc. Natl. Acad. Sci. U.S.A. 10110979

[3] Reisner W, Morton K, Riehn R, Wang Y, Yu Z, Rosen M, Sturm J, Chou S, Frey E and Austin R 2005 Phys. Rev. Lett. 9419610

[4] Reisner W, Beech J, Larsen N, Flyvbjerg H, Kristensen A and Tegenfeldt J 2007 Phys. Rev. Lett. 99058302

[5] Fu J, Yoo J and Han J 2006 Phys. Rev. Lett. 97018103

[6] Balducci A, Mao P, Han J and Doyle P 2006 Macromolecules 396273

[7] Mannion J T, Reccius C H, Cross J D and Craighead H G 2006 Biophys. J. 904538

[8] Riehn R, Lu M, Wang Y M, Lim S F, Cox E C and Austin R H 2005 Proc. Natl. Acad. Sci. U.S.A. 10210012

[9] Chou S Y, Krauss P R and Renstrom P J 1996 J. Vac. Sci. Tehcnol. B 144129

[10] Guo L J 2004 J. Phys. D: Appl. Phys. 37 R123

[11] Guo L J 2007 Adv. Mater. 19495

[12] Tan H, Gilbertson A and Chou S Y 1998 J. Vac. Sci. Tehcnol. B 163926

[13] Cheng X and Guo L J 2004 Microelectr. Eng. 71277

[14] Gersborg-Hansen M, Thamdrup L H, Mironov A and Kristensen A 2007 Microelectr. Eng. 841058

[15] Gates B D, Xu Q, Stewart M, Ryan D, Wilson C G and Whitesides G M 2005 Chem. Rev. 105 1171

[16] Bilenberg B, Schøler M, Shi P, Schmidt M S, Bøggild P, Fink M, Schuster C, Reuther F, Gruetzner C and Kristensen A 2006 J. Vac. Sci. Tehcnol. B 241776

[17] Bilenberg B, Jacobsen S, Schmidt M S, Skjolding L H D, Shi P, Bøggild P, Tegenfeldt J and Kristensen A 2006 Microelectr. Eng. 831609

[18] Persson F, Thamdrup L H, Mikkelsen M, Jarlgaard S, Skafte-Pedersen S , Bruus H and Kristensen H 2007 Nanotechnology 18245301

[19] Haas K H and Wolter H 1999 Current Opinion in Solid State and Materials Science 4571 
[20] Bilenberg B, Hansen M, Johansen D, Özkapici V, Jeppesen C, Szabo P, Obieta I M, Arroyo O, Tegenfeldt J and Kristensen A 2005 J. Vac. Sci. Tehcnol. B 232944

[21] Nielsen T, Nilsson D, Bundgaard F, Shi P, Szabo P, Geschke O and Kristensen A 2004 J. Vac. Sci. Tehcnol. B 221770

[22] Piruska A, Nikcevic I, Lee S H, Ahn C, Heineman W R, Limbacha P A and Seliskar C J 2005 Lab Chip 51348

[23] Niklaus F, Stemme G, Lu J Q and Gutmann R J 2006 J. Appl. Phys. 99031101

[24] Klank H, Kutter J P and Geschke O 2002 Lab Chip 2242

[25] Kricka L J, Fortina P, Panaro N J, Wilding P, Alonso-Amigo G and Becker H 2002 Lab Chip 21

[26] Abgrall P, Low L N and Nguyen N T 2007 Lab Chip 7520

[27] Bilenberg B, Nielsen T, Clausen B and Kristensen A 2004 J. Micromech. Microeng. 14814

[28] Guo L J, Cheng X and Chou C F 2004 Nano Lett. 469

[29] Mair D A, Geiger E, Pisano A P, Fréchet J M J and Svec F 2006 Lab Chip 61346

[30] Sinden R R 1994 DNA Structure and Function (San Diego: Academic Press, Inc.) p 23

[31] Glazer A N and Rye H S 1992 Nature 359859

[32] Bakajin O B, Duke T A J, Chou C F, Chan S S, Austin R H and Cox E C 1998 Phys. Rev. Lett. 802737

[33] Smith S B, Finzi L and Bustamante C 1992 Science 2581122

[34] Perkins T, Smith D E, Larson R G and Chu S 1995 Science 26883

[35] Carlsson C, Larsson A and Jonsson M 1996 Electrophoresis 17642

[36] Vologodskii A and Cozzarelli N 1995 Biopolymers 35289

[37] Rubinstein M and Colby R H 2003 Polymer Physics (Oxford: Oxford University Press) p 57

[38] Schaefer D W, Joanny J F and Pincus P 1980 Macromolecules 131280

[39] de Gennes P G 1979 Scaling Concepts in Polymer Physics (Ithaca: Cornell University Press) 